\title{
JAK Inhibitors in Rheumatoid Arthritis: An Evidence-Based Review on the Emerging Clinical Data
}

\section{Robert Harrington* Shamma Ahmad Al Nokhatha* Richard Conway (D)}

Department of Rheumatology, St. James's Hospital, Dublin, Ireland

*These authors contributed equally to this work
Correspondence: Richard Conway Department of Rheumatology, St. James's Hospital, Dublin, Ireland

Email drrichardconway@gmail.com
This article was published in the following Dove Press journal: Journal of Inflammation Research

\begin{abstract}
Janus kinase (JAK) Inhibitors are the latest drug class of disease-modifying medication to emerge for the treatment of rheumatoid arthritis (RA). They are a small molecule-targeted treatment and are the first oral option to compare favourably to existing biologic disease-modifying anti-rheumatic drugs (DMARDs). Tofacitinib, baricitinib and upadacitinib are the first 3 JAK inhibitors to become commercially available in the field and are the core focus of this review. To date, they have demonstrated comparable efficacy to tumour necrosis factor (TNF) inhibitors in terms of American College of Rheumatology (ACR) response rates and disease activity (DAS28) scores with similar cost to the benchmark adalimumab. This narrative review article aims to synthesise and distil the key available trial data on JAK inhibitor efficacy and safety, along with their place in the ACR and European League Against Rheumatism (EULAR) guidelines for RA. The novel mechanism of action of the JAK/STAT pathway is highlighted along with the potential effects of modulating each pathway. The rapid onset of action, role in attenuation of central pain processing and effect on structural damage and radiographic progression are also all examined in detail. We also explore the latest meta-analyses and comparative performance of each of the 3 available JAKs in an effort to determine which is most efficacious and which has the most favourable safety profile. Post marketing concerns regarding thromboembolism risk and herpes zoster infection are also discussed. Additionally, we review the cost-benefit analyses of the available JAK inhibitors and address some of the pharmacoeconomic considerations for real-world practice in the UK and US by detailing the raw acquisition cost and the value they provide in comparison to the benchmark biologic adalimumab and the anchor DMARD methotrexate.
\end{abstract}

Keywords: rheumatoid arthritis, immunosuppressive therapies, JAK inhibitors, targeted synthetic DMARD, tsDMARD

\section{Introduction}

Rheumatoid arthritis (RA) is a systemic chronic inflammatory disease, causing progressive damage to the synovial lining of joints. Left untreated RA can cause significant pain, deformity, loss of manual function and deterioration in overall quality of life. Since the late 1990s, methotrexate (MTX) has been the anchor disease-modifying antirheumatic drug (DMARD) for RA. ${ }^{1}$ While MTX was an undoubted breakthrough in treatment options, not all patients achieve the desired response with approximately $30 \%$ discontinuing treatment within the 1 st year due to a lack of efficacy or side effects. $^{2}$ As a result, there has been a continued drive to better understand the 
pathophysiology of RA and explore other potential therapeutic targets in an effort to develop and bring to market more viable treatments and alternatives.

The past two decades have seen the introduction of multiple biologic DMARDs (bDMARDs) which were seen as a less crude and more targeted form of immunosuppression than the broader effects of MTX, which was originally developed as a form of chemotherapy in the 1950s. Despite the arrival of tumour necrosis factor (TNF) inhibitors, B cell depletion of CD20 cells and interleukin 6 (IL-6) inhibition, there remains a sizeable cohort of RA patients with suboptimal control, loss of response or intolerability to the existing bDMARDs.

The newest class of drugs in RA treatment are the Janus kinase (JAK) inhibitors. JAK inhibitors are small-molecule oral treatments which have become widely available and they offer the first truly clinically efficacious long-term oral biologic option in RA. The discovery of the role of the JAK and the signal transducer and activator of transcription (STAT) constituents in cytokine signalling and RA pathogenesis has resulted in firstly, a novel targeted therapy and secondly, a targeted low molecular mass drug that can pass the lipid bilayer of the cellular membrane. As such JAK inhibitors were initially heralded for their targeted "smarter" mechanism of action and their oral route of delivery which was perceived as being very appealing to patients. However, in contrast, much has been written about herpes zoster infection rates, venous thromboembolism (VTE) risk, comparative clinical efficacy with established biological diseasemodifying anti-rheumatic drugs (bDMARDs), radiographic structural progression over time, and the role of the JAK/ STAT pathway on pain perception in central pain syndromes. This review will focus on the Jaki currently available for use in rheumatic diseases, tofacitinib, baricitinib and upadacitinib. Other Jaki that are in late-phase clinical trials or used in other diseases (peficitinib decernotinib, itacitinib, ruxolitinib) will not be the focus of this review.

\section{The JAK/STAT Pathway}

The JAK family is comprised of several different subtypes, notably JAK1, JAK2, JAK3 and TYK2 in addition to a multitude of STAT proteins, STAT 1, STAT2, STAT3, STAT4, STAT5a, STAT5b and STAT6. The pathway is initiated by a ligand/cytokine acting as an extracellular signal and binding to a receptor on the cell membrane which in turn causes a structural or conformational change and thus consequent activation of the implicated JAK isoforms that are either homodimers or heterodimers. Via a process of
JAK auto-phosphorylation, a docking site is created for the STAT protein which itself undergoes phosphorylation upon binding. The JAKs facilitate transportation or translocation of the STAT proteins into the cell nucleus whereby gene expression is initiated followed by protein synthesis.

The main cytokines that operate through the JAK/ STAT pathway include interleukins IL4, IL-6, IL 10, IL12, IL-23, granulocyte-macrophage colony-stimulating factor (GM-CSF), granulocyte colony-stimulating factor (G-CSF), erythropoietin (EPO), thrombopoietin (TPO), leptin and growth hormone $(\mathrm{GH})$, Table $1 .^{3-5}$

Figure 1 demonstrates a simplified illustration of the functional effect of the JAK/STAT signalling pathway. Various different combinations of JAKs and STATs assemble into complex multimers with a wide range of resultant biochemical and biophysiological effects within the cell and on the host at a broader systemic level, Table 1. Deficiencies of certain JAKs, or indeed genetic gain of functions of other JAKs, are the aberrant pathological basis of a broad spectrum of disease states. Gain of function genetic mutations in JAK1 can cause lymphoid neoplasms while gain of function mutations in JAK2 can cause myeloproliferative neoplasms. ${ }^{6-9}$ JAK3 genetic loss of function is strongly linked to Severe Combined Immunodeficiency (SCID) while STAT3 deficiency is associated with Hyper-IgE syndrome and interestingly chronic activation of JAK2-STAT3 by leptin and IL-6

Table I JAK/STAT and Cytokine Interactions

\begin{tabular}{|l|l|l|}
\hline Cytokine & JAKs & Broad Effect \\
\hline IFN $\alpha$, IFN $\beta$, IL-I0 & $\begin{array}{l}\text { JAKI \& } \\
\text { TYK2 }\end{array}$ & Antiviral Immunity \\
\hline IFN $\gamma$ & $\begin{array}{l}\text { JAKI \& } \\
\text { JAK2 }\end{array}$ & Antiviral Immunity \\
\hline IL-6, IL-II & $\begin{array}{l}\text { JAKI, JAK2 } \\
\text { \& TYK2 }\end{array}$ & $\begin{array}{l}\text { Acute Phase } \\
\text { Inflammatory } \\
\text { Response }\end{array}$ \\
\hline IL-I2, IL-23 & $\begin{array}{l}\text { JAK2 \& } \\
\text { TYK2 }\end{array}$ & $\begin{array}{l}\text { ThI7 Cell } \\
\text { Differentiation }\end{array}$ \\
\hline $\begin{array}{l}\text { IL-2, IL-4, IL-7, IL-9, IL-13, } \\
\text { IL-I5, IL-I9, IL-2I }\end{array}$ & $\begin{array}{l}\text { JAKI \& } \\
\text { JAK3 }\end{array}$ & $\begin{array}{l}\text { White Cell } \\
\text { Differentiation }\end{array}$ \\
\hline $\begin{array}{l}\text { G-CSF, GM-CSF, EPO, TPO, } \\
\text { IL-3, IL-5 } \\
\text { Growth hormone, prolactin } \\
\text { Leptin }\end{array}$ & $\begin{array}{l}\text { JAK2 \& } \\
\text { JAK2 }\end{array}$ & $\begin{array}{l}\text { Myeloid Cell } \\
\text { Differentiation } \\
\text { Metabolic homeostasis }\end{array}$ \\
\hline
\end{tabular}

Note: Data from references 13 and 14 . 


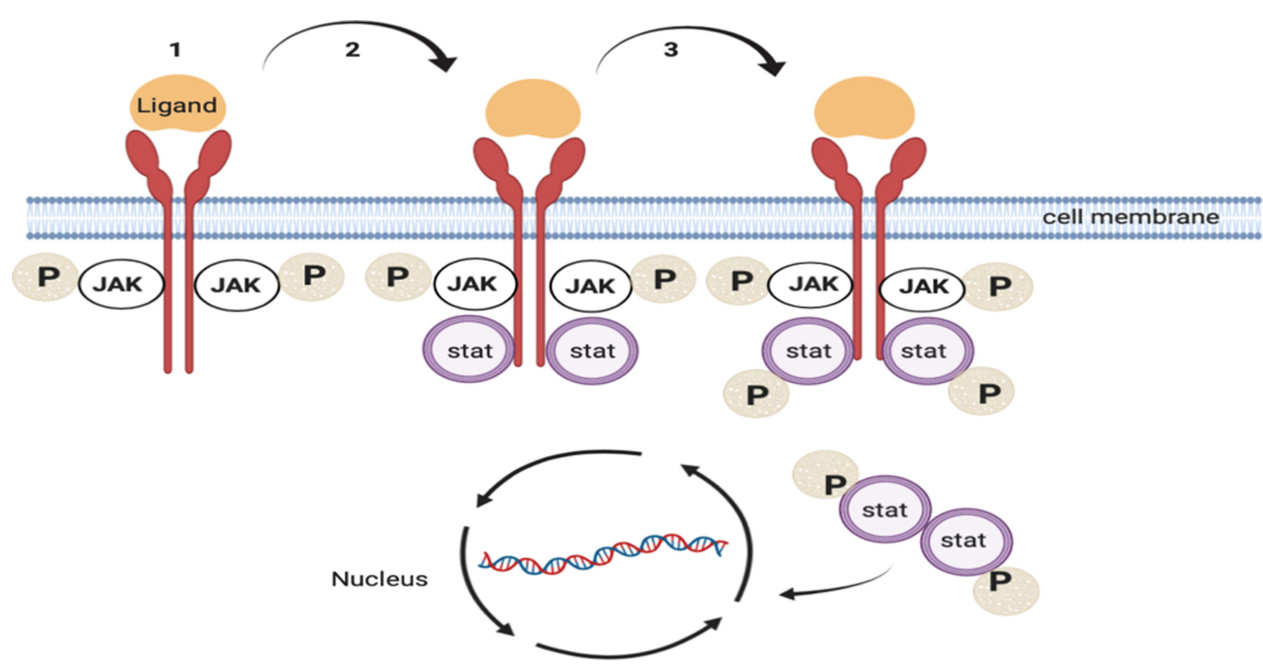

Figure I Simplified representation of the JAK/STAT signalling pathway: I. Ligand binding to the extra-cellular domain of the homodimer or heterodimer cytokines receptor, the latter is activated and auto-phosphorylation occurs, 2. STAT proteins bind to the activated receptor, 3. STAT proteins are phosphorylated followed by nucleus translocation and protein synthesis.

has been linked with obesity due to impair proper leptin and insulin action. ${ }^{10-12}$

\section{JAK Inhibitors in Rheumatoid Arthritis}

Tofacitinib was the first commercially available JAK inhibitor developed and brought to market for the treatment of RA. Its development was undertaken in the mid-1990s by a joint public-private partnership between the National Institute of Health (NIH) and Pfizer. ${ }^{13}$ It was approved by the Food and Drug Administration (FDA) in November 2012 at 5mg BD dose and brought to market under the brand name Xeljanz. The original target cohort was intended to be adults with moderately to severely active RA who have had an inadequate response to, or who are intolerant of methotrexate. ${ }^{14}$ Tofacitinib was finally approved by the European Medicines Agency (EMA) in March 2017 after over 4 years of postmarketing safety surveillance in North America.

Further interest in the JAK pathway within the pharmaceutical industry resulted in the development of Baricitinib (Oluminant) by Eli Lilly and Upadacitinib (Rinvoq) by AbbVie, receiving FDA approval in May 2018 and August 2019, respectively. There are a few key differences in the therapeutic targets of each of JAK inhibitor. Tofacitinib is a pan JAK inhibitor with greater selectivity for JAK1/JAK3 with minor activity on JAK2 and TYK2. Baricitinib is a JAK1/JAK2 inhibitor with moderate activity against TYK2 and minimal activity against JAK3 ${ }^{15,16}$ Upadacitinib aims to solely target the JAK1 pathway. The rationale here being that more specific selectivity of JAK inhibition may reduce dose-related toxicity and side effects without a significant loss of efficacy. ${ }^{17}$ Currently, commercially available JAK inhibitors are detailed in Table 2.

\section{Tofacitinib Efficacy and Radiographic Progression}

During the FDA approval process, all 7 of tofacitinib's Phase III randomised control trials (RCTs) showed the efficacy of inhibiting JAK1/JAK3 in RA. ORAL-START demonstrated significantly higher ACR20, ACR50 and ACR70 response rates in tofacitinib $5 \mathrm{mg}$ and $10 \mathrm{mg}$ BD dosing than MTX monotherapy at both 6 and 24 months. ${ }^{18}$ A post hoc study of ORAL-SCAN highlighted tofacitinib's efficacy versus placebo regardless of the background methotrexate dose. ${ }^{19}$ In ORAL-STRATEGY, tofacitinib + MTX was noninferior to adalimumab + MTX. However, tofacitinib monotherapy did not fare as favourably as the combination of adalimumab + MTX. This suggests that the synergistic effect of tofacitinib + MTX is preferable to tofacitinib monotherapy in moderate to severe RA in terms of disease control, if the combination is tolerable for the patient. ${ }^{20}$ Progression of structural joint damage was also assessed using the modified van der Heijde Total Sharp Score. In ORAL-START, tofacitinib monotherapy was shown to be superior to MTX monotherapy in limiting progression of structural damage. ${ }^{18}$

\section{Baricitinib Efficacy and Radiographic Progression}

Baricitinib successfully progressed through 4 global phase III RCTs during the approval process. In RA-BEGIN, 
Table 2 Commercially Available JAK Inhibitors

\begin{tabular}{|c|c|c|c|c|c|c|c|}
\hline \multicolumn{8}{|c|}{ JAK Inhibitors in RA } \\
\hline $\begin{array}{l}\text { JAK } \\
\text { Inhibitor }\end{array}$ & $\begin{array}{l}\text { Pharma } \\
\text { Company }\end{array}$ & $\begin{array}{l}\text { Target } \\
\text { (Selectivity) }\end{array}$ & Trials & $\begin{array}{l}\text { Recommended } \\
\text { Dose }\end{array}$ & FDA Approval & $\begin{array}{l}\text { EMA } \\
\text { Approval }\end{array}$ & $\begin{array}{l}\text { Japan } \\
\text { Approval }\end{array}$ \\
\hline $\begin{array}{l}\text { Tofacitinib } \\
\text { (Xeljanz) }\end{array}$ & Pfizer & $\begin{array}{l}\text { JAKI \& JAK3 } \\
\text { (strong/high) } \\
\text { JAK2 (minor) } \\
\text { TYK2 (minor) }\end{array}$ & $\begin{array}{l}\text { ORAL Solo }{ }^{63} \\
\text { ORAL Standard } \\
\text { ORA } \\
\text { ORAL Scan } \\
\text { ORAL Step } \\
\text { Or6 } \\
\text { ORAL Sync }{ }^{67} \\
\text { ORAL Start } \\
\text { ORAL Strategy } \\
\text { ORA } \\
\text { ORAL Sequel }\end{array}$ & $\begin{array}{l}5 \mathrm{mg} B D \\
1 \mathrm{Img} \mathrm{OD}\end{array}$ & November 2012 & $\begin{array}{l}\text { March } \\
2017\end{array}$ & March 2013 \\
\hline $\begin{array}{l}\text { Baricitinib } \\
\text { (Olumiant) }\end{array}$ & Lilly & $\begin{array}{l}\text { JAK1 \& JAK2 } \\
\text { (strong/high) } \\
\text { TYK2 (moderate) } \\
\text { JAK3 (minor) }\end{array}$ & $\begin{array}{l}\text { Phase } 2 \\
\text { NCT00902486 } \\
\text { Phase2b } \\
\text { NCT0I I } 85353^{70} \\
\text { Phase } 2 b \\
\text { NCT0I } 469013^{71} \\
\text { RA-Beacon } \\
\text { RA-Build } \\
\text { RA-Begin }{ }^{21} \\
\text { RA-Beam }{ }^{74} \\
\text { RA-Balance } \\
\text { RA-Beyond } \\
\text { R6 }\end{array}$ & $\begin{array}{l}2 \mathrm{mg} \text { OD } \\
4 \mathrm{mg} \text { OD }\end{array}$ & $\begin{array}{l}\text { May } \\
2018\end{array}$ & February 2017 & $\begin{array}{l}\text { July } \\
2017\end{array}$ \\
\hline $\begin{array}{l}\text { Upadacitinib } \\
\text { (Rinvoq) }\end{array}$ & AbbVie & JAKI (strong/high) & $\begin{array}{l}\text { SELECT-Beyond }^{77} \\
\text { SELECT-Next }^{78} \\
\text { SELECT- } \\
\text { Monotherapy }^{79} \\
\text { SELECT-Choice } \\
\text { SELECT- } \\
\text { SELE } \\
\text { Compare }^{81} \\
\text { SELECT-Early } \\
\text { NCT029552/2 }\end{array}$ & $15 \mathrm{mg}$ OD & August 2019 & December 2019 & January 2020 \\
\hline $\begin{array}{l}\text { Filgotinib } \\
\text { (Jyseleca) }\end{array}$ & $\begin{array}{l}\text { Gilead \& } \\
\text { Galapagos }\end{array}$ & JAKI (strong/high) & $\begin{array}{l}\text { DARWINI }{ }^{83} \\
\text { DARWIN2 }{ }^{84} \\
\text { DARWIN3 } \\
\text { NCT02065700 } \\
\text { FINCHI } \\
\text { NCT02889796 } \\
\mathrm{FINCH2}^{85} \\
\text { FINCH3 } \\
\text { NCT02886728 } \\
\text { FINCH4 } \\
\text { NCT03025308 }\end{array}$ & $\begin{array}{l}100 \mathrm{mg} \text { OD } \\
200 \mathrm{mg} \text { OD }\end{array}$ & - & - & - \\
\hline $\begin{array}{l}\text { Peficitinib } \\
\text { (Smyraf) }\end{array}$ & $\begin{array}{l}\text { Astellas } \\
\text { Pharma }\end{array}$ & $\begin{array}{l}\text { JAK3 (moderate) } \\
\text { JAKI (minor) } \\
\text { JAK2 (minor) } \\
\text { TYK2 (minor) }\end{array}$ & $\begin{array}{l}\text { RAJ1 }{ }^{86} \\
\text { RAJ } 2^{87} \\
\text { RAJ3 }{ }^{88} \\
\text { RAJ } 4^{89}\end{array}$ & $\begin{array}{l}100 \mathrm{mg} \text { OD } \\
150 \mathrm{mg} \text { OD }\end{array}$ & - & - & March 2019 \\
\hline Decernotinib & Vertex & JAK3 (strong/high) & Discontinued & & & - & \\
\hline
\end{tabular}

(Continued) 
Table 2 (Continued).

\begin{tabular}{|c|c|c|c|c|c|c|c|}
\hline \multicolumn{8}{|c|}{ JAK Inhibitors in RA } \\
\hline $\begin{array}{l}\text { JAK } \\
\text { Inhibitor }\end{array}$ & $\begin{array}{l}\text { Pharma } \\
\text { Company }\end{array}$ & $\begin{array}{l}\text { Target } \\
\text { (Selectivity) }\end{array}$ & Trials & $\begin{array}{l}\text { Recommended } \\
\text { Dose }\end{array}$ & FDA Approval & $\begin{array}{l}\text { EMA } \\
\text { Approval }\end{array}$ & $\begin{array}{l}\text { Japan } \\
\text { Approval }\end{array}$ \\
\hline Itacitinib & Incyte & JAKI (strong/high) & NCT0162657390 & $\begin{array}{l}100 \mathrm{mg} \text { BID } \\
300 \mathrm{mg} \text { QD } \\
200 \mathrm{mg} \text { BID } \\
600 \mathrm{mg} \text { QD }\end{array}$ & - & - & - \\
\hline $\begin{array}{l}\text { Ruxolitinib } \\
\text { (Jakavi) }\end{array}$ & $\begin{array}{l}\text { Incyte Corp } \\
\text { (US) } \\
\text { Novartis }\end{array}$ & $\begin{array}{l}\text { JAKI \& JAK2 } \\
\text { (strong/high) }\end{array}$ & NCT0055004391 & $\begin{array}{l}5 \mathrm{mg} \text { BID } \\
15 \mathrm{mg} \text { BID } \\
25 \mathrm{mg} \text { BID } \\
50 \mathrm{mg} \text { QD }\end{array}$ & - & - & - \\
\hline
\end{tabular}

Note: Data from references 17-21.

baricitinib monotherapy and baricitinib + MTX was compared with MTX monotherapy in RA patients with little to no prior conventional DMARD use. Comparison was favourable with baricitinib monotherapy demonstrating superior efficacy to MTX monotherapy at 24 weeks with a p-value of less than 0.01. Statistically significant improvements were consistently observed in baricitinib monotherapy and baricitinib + MTX compared to MTX monotherapy for ACR20, ACR50 and ACR70 response rates. $^{21}$

In RA-BEAM, baricitinib, both as monotherapy and in combination with MTX, was compared with adalimumab and placebo in biologic naïve RA patients with poor response to prior MTX treatment. Baricitinib was found to be non-inferior to adalimumab at week 12 for the ACR20 response with a noninferiority margin of $12 \%$ (70\% vs $61 \%$, $95 \%$ confidence interval for the difference between groups, $2 \%$ to $15 \%$ ). The authors note that according to the statistical analysis plan, it can be deduced that baricitinib was as a result significantly superior to adalimumab $(p<0.01)$. Furthermore, baricitinib was superior to adalimumab with respect to the mean change in DAS28-CRP score at week 12 $(-2.24$ for baricitinib and -1.95 for adalimumab, $\mathrm{p}<0.001)$. Baricitinib's time to effect is also noted as a strength of the medication, with significant superiority to placebo after 1 week and to adalimumab at 2 to 4 weeks.

Reduction in radiographic progression using the modified van der Heijde score was seen at week 24 for both baricitinib and adalimumab when compared with placebo. $^{22}$ Baricitinib + MTX also demonstrated statistically superior reduction in radiographic progression when compared with MTX monotherapy. ${ }^{23}$

\section{Upadacitinib Efficacy and Radiographic Progression}

As a JAK1 inhibitor, upadacitinib tested the hypothesis that selective inhibition of only JAK1 could obtain the same clinical efficacy in RA treatment as a more nonselective JAK inhibitor such as tofacitinib and baricitinib, while achieving a better safety profile. In the SELECTEARLY and SELECT-MONOTHERAPY RCTs, upadacitinib showed a significantly greater clinical response at $15 \mathrm{mg}$ and $30 \mathrm{mg}$ compared to MTX in ACR50 response $(52.1 \%, 56.4 \%$, and $28.3 \%, \mathrm{p}<0.001)$ and DAS28-CRP $<2.6$ rate $(35.6 \%, 40.8 \%$, and $13.7 \%)$ at week $12 .^{24,25}$

In SELECT-COMPARE, upadacitinib + MTX was compared with adalimumab + MTX in RA patients with previous inadequate response to MTX. At week 12 superiority was achieved for upadacitinib + MTX versus adalimumab + MTX with ACR $20(70.5 \%$ vs 63\%, p<0.05), ACR50 (45.2\% vs 29.1\%, p<0.01) and DAS28-CRP $\leq 3.2$ (45.0\% vs $28.7 \%)$. Using the modified van der Heijde score, erosion score, and joint space narrowing as metrics of radiographic progression, upadacitinib and adalimumab performed similarly. Significantly more patients randomised to upadacitinib $(86 \%)$ or adalimumab $(88 \%)$ had no radiographic progression versus placebo $(74 \%)$ $(\mathrm{p} \leq 0.001)^{26}$

\section{Comparative Efficacy of the Approved JAK Inhibitors for RA}

To date, there has not been a head-to-head trial for any of the available JAK inhibitors approved in RA. In attempting to answer this question Lee \& Song performed a network meta-analysis. ${ }^{27}$ This meta-analysis included 4 
RCTs; namely ORAL Strategy, RA-BEAM, FINCH1 \& Fleischman 2019. 22,26,28,29

This meta-analysis showed that in RA patients with an inadequate response to MTX, baricitinib 4mg + MTX and upadacitinib 15mg + MTX showed the highest ACR response rates. Additionally, it demonstrated a significantly higher ACR20 response rate with both baricitinib 4mg + MTX and upadacitinib $15 \mathrm{mg}+$ MTX when compared to adalimumab 40mg + MTX. With regard to the issue of herpes zoster infection (HZV), placebo + MTX ranked as the safest treatment in terms of risk of HZV infection, with baricitinib + MTX carrying the highest risk of infection. Interestingly, filgotinib 200mg + MTX ranked as the 2nd safest combination strongly suggesting that discrete targeting of JAK1 alone carries similar efficacy with an improved safety and side effect profile compared to non-specific JAK inhibition. The authors do note however that adalimumab + MTX carries the lowest risk or probability of a severe adverse event (SAE) while baricitinib + MTX carries the highest risk. ${ }^{27}$

Given adalimumab is the common comparator in all 4 RCTs and it is also the most commonly prescribed bDMARD in our country, we have used these trials for our own meta-analysis (Figure 2). Using Cochrane's RevMan 5 meta-analysis software and a Mantel Haenszel test with fixed effects, the following forest plots for multiple JAK inhibitors and the comparator adalimumab were created for the odds ratio of achieving ACR20, 50 and 70 response rates. The results of this analysis would suggest that both baricitinib 4mg OD + MTX and upadacitinib 15mg OD + MTX are superior to adalimumab 40mg + MTX in terms of achieving a meaningful ACR70 response rate.

\section{Side Effect Profile}

The most frequently reported adverse events with JAK inhibitor treatment in RA patients are infections. ${ }^{30}$ While the incidence of common infections such as upper respiratory tract, lower respiratory tract, and urinary tract infections are higher compared with the general population, the incidence is still similar to bDMARDs. ${ }^{30,31}$ It is notable that trials to date suggest a lower risk of infection with tofacitinib in comparison to TNF inhibitors, rituximab and tocilizumab, JAK inhibitors carry a slightly lower rate of severe infection with a frequency of (2.7-3.1) per 100 patient-years as compared to between 3 and 5 per 100 patient-years in bDMARDs. Tuberculosis was seen at a frequency of 1.5 per 1000 patient-years. As a result, quantiferon testing should still be performed as part of screening prior to introduction of JAK inhibitors. ${ }^{30-32}$

\section{Herpes Zoster Infection}

Herpes zoster (HZV) infection is seen more frequently in RA patients compared with the background population. Much of the risk can be attributed to age and the immunosuppression secondary to chronic use of corticosteroids. ${ }^{33}$ However, the exploration and development of drugs acting on the JAK pathway raised concern of markedly increased risk of HZV infection. Pooling data from tofacitinib RCTs revealed an incidence rate of HZV 1.5 to 2 fold higher than normally seen in the RA population and higher than the observed rate in those on bDMARDs. Some of the risks can be explained by geographic distortion or ethnicity as rates of HZV were increased in Asia at 9.2 per 100 patient-years and India at 8.9 patients. Rates were significantly lower in Western Europe and North America at 2.7 and 3.3 per 100 patient-years respectively. This may reflect the effect of downregulation of interferons and $\mathrm{IL}-15$ responsible for viral elimination. Reassuringly, multi-dermatomal, and disseminated herpes zoster were uncommon, with no cases of visceral disease or death with tofacitinib treatment. ${ }^{34,35}$

\section{Cytopenias}

Cytopenias can be seen with all JAK inhibitors in clinical use in RA. It is this cytopenic effect that is the mechanism of action of the JAK inhibitor Ruxolitinib which is used in myeloproliferative disorders. As mentioned previously, it is well known that the JAK2 pathway is implicated in lymphomas and leukaemias, so while JAK inhibitors may have a protective effect in this regard, the physician needs to remain vigilant of cytopenia, particularly the effects of neutropenia and lymphopenia and the risk of infection this confers. ${ }^{32,36,37}$ Although cytopenia is a common adverse effect of JAKi, there are multiple reasons for anaemia in RA, and tofacitinib can slightly increase haemoglobin level due to less inhibitory effect on JAK2 which is responsible for erythropoietin signalling. Paradoxical transient modest elevation of platelets has been noticed with baricitinib at 2 weeks, hypothesised to be due to suboptimal dosing, but no negative consequences of this have been reported. ${ }^{34,38,39}$

\section{Thrombosis}

The FDA and post-marketing safety surveillance have revealed an increase in risk of pulmonary embolism (PE) and death with the 10mg twice daily dose of tofacitinib in 


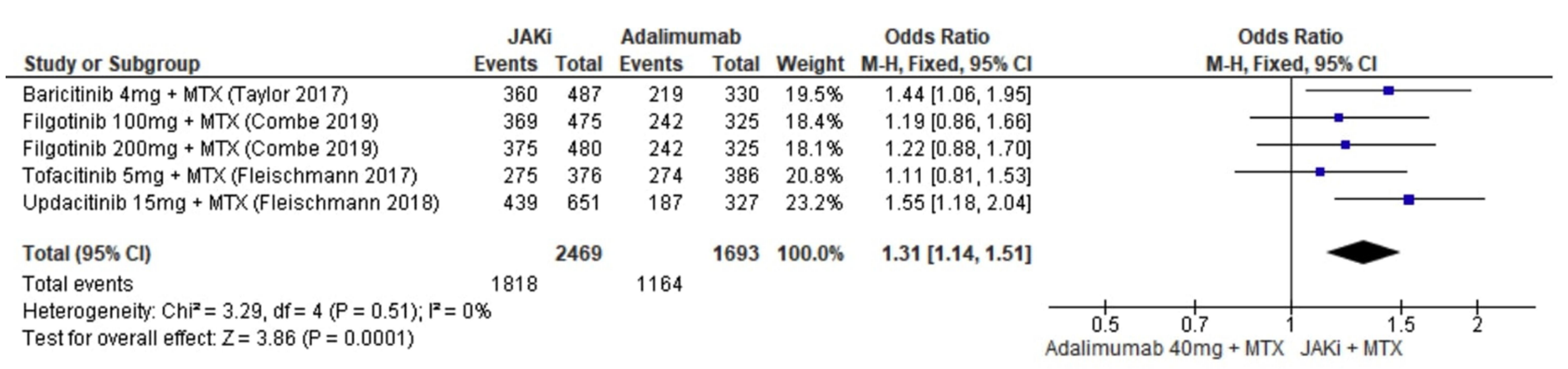

\section{ACR20 Response Rate Forest Plot}

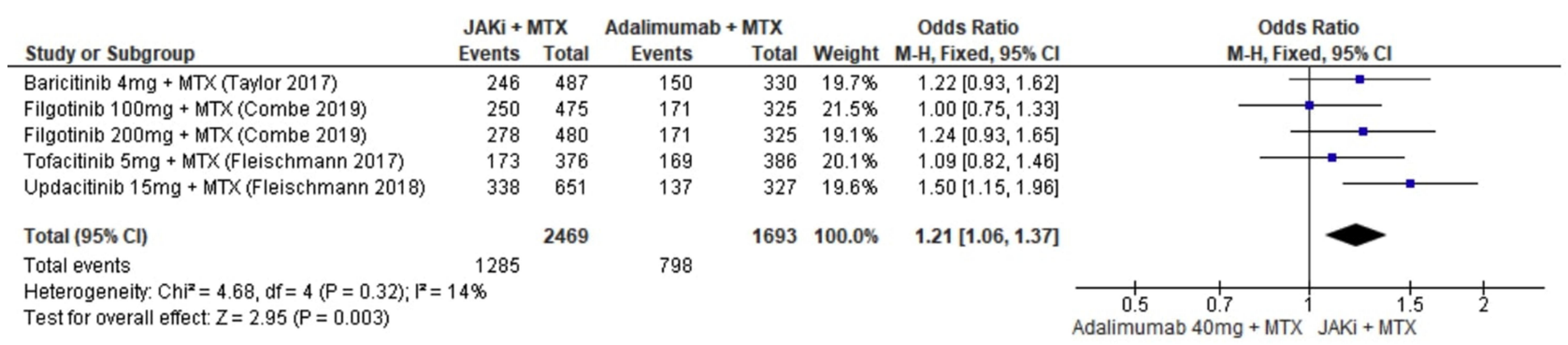

ACR50 Response Rate Forest Plot

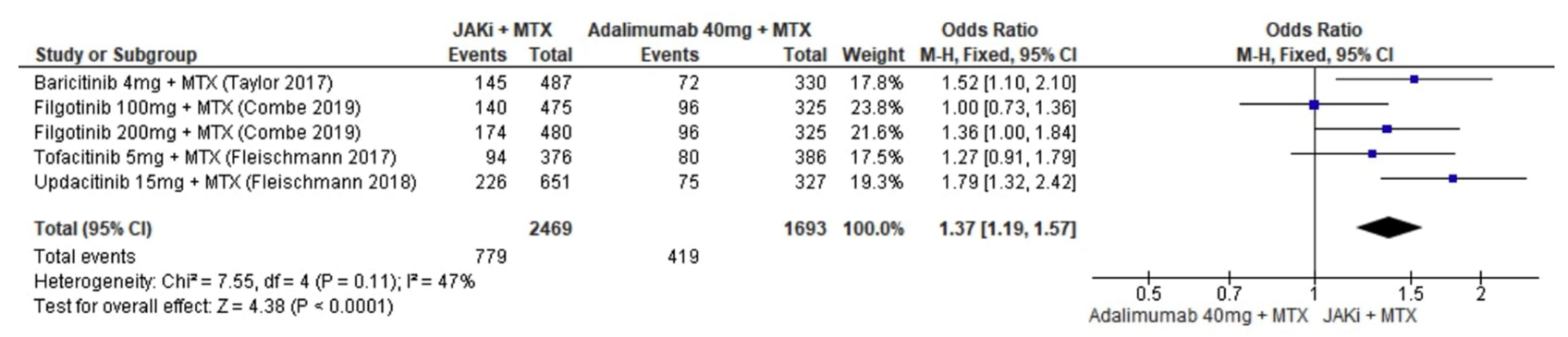

\section{ACR70 Response Rate Forest Plot}

Figure 2 Forest plot comparing the JAKs to adalimumab.

RA patients. This dose is not approved in RA and is only approved for ulcerative colitis. Discovery of this increased risk of PE over time is in contrast to the initial reassuring data derived from pooled analyses of RCTs. As a result, rheumatologists must be cognisant of a history of prior venous thromboembolism before considering commencing a JAK inhibitor. From the mechanism of action of JAK inhibitors, this risk is not immediately obvious since these medications can cause predominantly thrombocytopenia rather than thrombocytosis. ${ }^{30,40}$

\section{Malignancy}

To date, extensive meta-analyses have revealed no significantly increased risk of malignancies in patients treated with either tofacitinib or bDMARDs when compared to treat with cDMARDs or placebo. ${ }^{30,41}$

\section{Lipid Levels and Cardiovascular Events}

It is well established that tofacitinib and baricitinib increase LDL cholesterol in RA patients. ${ }^{34}$ It is believed chronic inflammation in the setting of RA causes falsely low levels of LDL which do not correlate with the increased atherosclerotic risk seen in RA and chronic inflammation. As a result, the current thinking is that both JAK inhibitors and bDMARDs correct these low levels of LDL without negatively impacting cardiovascular risk. The LDL/HDL ratio remains stable with JAK inhibitor treatment suggesting negligible impact on long-term 
cardiovascular risk. This is consistent with lipid profiles seen in psoriasis patients on tofacitinib treatment. ${ }^{32,37,42}$ Pooled studies on cardiovascular risk in RA patients on the approved doses of tofacitinib or baricitinib have not demonstrated an increase in risk compared with placebo. ${ }^{43}$

\section{Weight/Adiposity}

There is conflicting information on the effects of JAK inhibitors on adiposity in RA patients.

It is known than JAK2 is a component of the intracellular insulin-like growth factor 1 (IGF-1) and growth hormone $(\mathrm{GH})$ signalling axis. Weight gain is clearly demonstrated for ruxolitinib which is used in myeloproliferative disorders, but the same effect has also been observed with both tofacitinib and baricitinib. ${ }^{32,36,44,45}$ Conversely, a 2014 study discovered that tofacitinib was able to convert white adipocytes into the more metabolically active brown adipocytes, suggesting a possible mechanism of action that may have potential in the treatment of obesity. ${ }^{46}$ In younger RA patients, there is an argument that better disease control with JAK inhibitors will result in improved exercise capacity, and subsequent weight loss, due to reduced stiffness, pain and fatigue.

\section{Pain}

The measure or metric of effective RA disease control from the perspective of the rheumatologist and the patient are not necessarily one and the same. With bDMARDs becoming ubiquitous and the more recent introduction of the JAK inhibitor class, there has been a strict focus on the treat-to-target approach of inflammatory disease activity. The principal concerns of the patients however are the reduction of pain and fatigue and restoration of physical function and vitality. ${ }^{47-49}$

In a survey of 1204 RA patients, $68.6 \%$ reported pain as the most important area required for health improvement. ${ }^{50}$ From the physician's perspective, a lot of focus is directed at markers of inflammation and radiographic progression as the proxies for adequate disease control, while the patient's focus remains on pain reduction.

Pain in RA has generally been attributed to peripheral nociceptive aetiologies such as ongoing inflammation and synovial damage. ${ }^{51}$ However, patient reports of pain persistence after achieving strict disease activity targets are common. Despite normalisation of inflammatory markers, halting of radiographic progression and absence of synovitis clinically, pain often persists and subjective measures of quality life such as energy and fatigue levels do not improve. ${ }^{52,53}$ This strongly suggests that peripheral and central pain-processing mechanisms that are upregulated by repeated stimulus through inflammation are not effectively downregulated by traditional cDMARDs or bDMARDs, despite control of disease at the level of the synovium. It has been demonstrated that RA patients demonstrate heightened sensitivity to nociceptive stimuli. In conjunction with this, studies in rat models suggest that JAK/STAT signalling can promote mechanical pain sensitivity. ${ }^{54}$ Blocking IL-6 by targeting JAK-STAT3 activity in these animal models substantially reduces mechanical allodynia and suggests a potential role for JAK inhibitor use in humans for downregulating central pain processing pathways which are firing aberrantly due to prior chronic inflammation.

In terms of mechanism of action, tofacitinib blocks multiple cytokines via JAK3 but it also inhibits IL-6 via JAK1 inhibition. Indeed, some patients report pain relief within the first 24 hours of commencing JAK inhibitors, long before there is any biochemical improvement in CRP or ESR. ${ }^{55}$ The goal of determining differences between JAK inhibitors, TNF inhibitors, and IL- 6 inhibitors in improvement in pain and physical function was achieved through an extensive matching adjusted indirect comparison (MAIC) using data from RCTs. It determined that among patients naïve to cDMARDs and bDMARDs, baricitinib $4 \mathrm{mg}$ provides statistically significant greater pain reduction and improvement in physical function compared with adalimumab $40 \mathrm{mg}$ and tocilizumab $8 \mathrm{mg} / \mathrm{kg}$. There was no discernible difference between baricitinib and tofacitinib with respect to pain or physical function in 2 of 3 of these analyses. ${ }^{56}$

An important learning point to consider here is that baricitinib shows superior improvement in pain compared to adalimumab. One hypothesis suggests a role of GMCSF and IL6 in osteoarthritic and neuropathic pain, respectively. By targeting JAK2 signalling pain pathways are attenuated and downregulated. ${ }^{57}$ However, baricitinib does not show superior efficacy to adalimumab in terms of halting or retarding radiographic progression of structural damage. In fact, the modified van der Heijde score for adalimumab is superior to baricitinib at week 24 . Longitudinal studies over many years would be required to determine if there is a true difference in effect on structural damage between the two drugs. What can be said at this point is that in RA patients baricitinib is superior to adalimumab in pain improvement yet it is inferior to adalimumab in terms of the modified van der Heijde score 
at week 24. This in conjunction with the fact that some patients report pain reduction within the first 1 to 2 doses of tofacitinib or baricitinib implies that JAK inhibitors not alone decrease systemic inflammation in RA, but may also be efficacious in central pain syndromes.

\section{ACR and EULAR Guidelines}

The American College of Rheumatology (ACR) and the European League Against Rheumatism (EULAR) have produced congruent guidelines for the treatment of RA. While both the ACR 2015 and EULAR 2019 guidelines affirm MTX monotherapy as the 1st line treatment, JAK inhibitors are now considered a viable option as 2nd line treatment in moderate or high disease activity refractory to MTX monotherapy. JAK inhibitors are now viewed on equal footing with TNF inhibitors and non-TNF biologics such as abatacept, tocilizumab and rituximab. While it may take some time for physician prescribing practices to change, the availability of an equally efficacious oral option is particularly appealing to many patients. Figure 3 demonstrates a simplified flowchart of the existing treatment guidelines. ${ }^{58,59}$

\section{Pharmacoeconomic Considerations}

Drug class availability within public healthcare systems may differ from country to country and is based on robust cost-benefit analysis. Quality adjusted life years (QALYs) gives a useful metric for such pharmacoeconomic considerations within a healthcare system. Referral to the report on JAK inhibitors for RA by the Institute for Clinical and Economic Review (ICER) shows the relative cost of each treatment, Table 3. New treatments are benchmarked against the anchor cDMARD MTX and the most commonly prescribed bDMARD adalimumab. ${ }^{60}$

Using the raw wholesale acquisition cost (WAC) as the comparator, tofacitinib and baricitinib are approximately 68 and 32 times more expensive per annum than MTX monotherapy in the US. While both tofacitinib and baricitinib appear to compare favourably to adalimumab in the ICER report, it does not explain the full story given the variability in WAC country to country. There are multiple adalimumab biosimilars now available as AbbVie's Humira patent expired in Europe in 2017. For example, in the NHS, the acquisition cost is a fraction of that in the US. In 2018, as per the British National Formulary (BNF), the annual cost to the NHS for a year's supply of adalimumab is approximately $\$ 10,700$ as compared to approximately $\$ 60,000$ in the US cited in the National Average Drug Acquisition Cost (NADAC), Table 4. ${ }^{61,62}$ As per the $\mathrm{BNF}$, the annual cost of tofacitinib $5 \mathrm{mg} \mathrm{BD}$ in the UK is $£ 9000$ or $\$ 11,400$ in 2020 . This compares to $\$ 55,480$ in the US, again as per data from the NADAC.

Interestingly, the ICER report determined that there was sufficient evidence that upadacitinib plus cDMARD

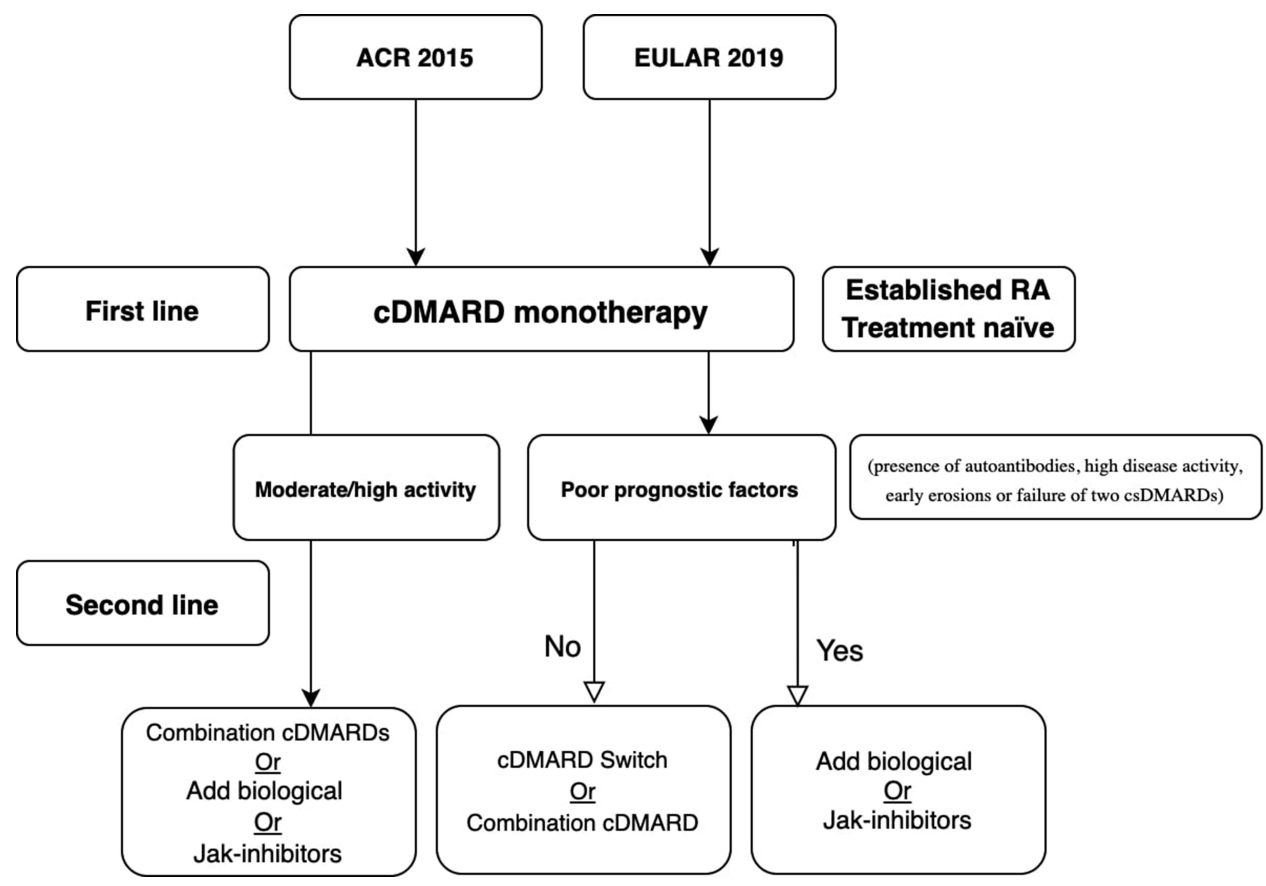

Figure 3 Simplified overview of ACR 2015 and EULAR 2019 guidelines for management of RA. 
Table 3 Drug Costs from ICER Report

\begin{tabular}{|l|l|l|l|l|l|}
\hline Drug & WAC per Unit & Discount from WAC & Net Price per Unit & Annual WAC & Annual Net Price \\
\hline Upadacitinib 15mg Tab & $\$ 163.89$ & $26 \%$ & $\$ 120.56$ & $\$ 59,680$ & $\$ 44,035$ \\
Baricitinib 2mg Tab & $\$ 71.23$ & $19 \%$ & $\$ 57.59$ & $\$ 26,017$ & $\$ 21,033$ \\
Tofacitinib 5mg Tab & $\$ 74.68$ & $34 \%$ & $\$ 49.50$ & $\$ 54,552$ & $\$ 36,159$ \\
Adalimumab 40mg/0.8mL sol & $\$ 2587.05$ & $34 \%$ & $\$ 1696.21$ & $\$ 67,263$ & $\$ 44,102$ \\
Methotrexate 2.5mg Tab & $\$ 2.55$ & - & $\$ 2.55$ & $\$ 796$ & $\$ 796$ \\
\hline
\end{tabular}

Note: Data from reference 95.

Table 4 US vs UK Pharmacoeconomic Comparison June 2020 (US Dollars)

\begin{tabular}{|l|l|l|l|}
\hline & $\begin{array}{l}\text { MTX Annual } \\
\text { Acquisition } \\
\text { Cost }\end{array}$ & $\begin{array}{l}\text { Adalimumab } \\
\text { Annual } \\
\text { Acquisition Cost }\end{array}$ & $\begin{array}{l}\text { Tofacitinib } \\
\text { Annual } \\
\text { Acquisition Cost }\end{array}$ \\
\hline US & $\$ 796$ & $\$ 60,000$ & $\$ 55,480$ \\
UK & $\$ 233$ & $\$ 10,700$ & $\$ 11,400$ \\
\hline
\end{tabular}

Note: Data from references 93 and 94 .

provided net health benefit compared to adalimumab plus cDMARD. However, they did not find sufficient evidence that tofacitinib plus CDMARD provided net health benefit compared to adalimumab plus cDMARD. In Europe, pharmacoeconomic considerations may be very different within public healthcare systems, making the JAK inhibitors attractive options.

\section{Conclusion}

The JAK inhibitors are a rapidly developing treatment space in RA. They offer a targeted oral therapy with comparable efficacy to TNF inhibitors while maintaining a similar safety profile. Their oral formulation makes them a particularly appealing treatment option for patients. Early pain relief seems to occur before the return of inflammatory markers to normal, suggesting a possible role in attenuation of central pain processing. In relation to this, there is objective measurable efficacy from as early as 2 weeks with maximum effect beyond 3 months. To date, upadacitinib $15 \mathrm{mg}+$ MTX and baricitinib $4 \mathrm{mg}+$ MTX demonstrate the highest ACR response rates. With regards to SAEs, HZV risk is increased but multidermatomal or disseminated infection is very rare. The FDA has identified an increased risk of thrombophilia with JAK inhibitors and tofacitinib in RA is only approved at the $5 \mathrm{mg}$ BD dose. Careful consideration should be given to VTE when deciding on suitability for 2 nd line treatment. JAKi have been incorporated into the ACR and EULAR guidelines for treatment of moderate to severe
RA refractory to MTX monotherapy. It is anticipated that JAK inhibitors will be increasingly used as prescribing practices change with long-term safety and efficacy data.

\section{Executive Summary}

JAK inhibitors are a rapidly developing treatment space.

JAK inhibitors demonstrate comparable efficacy to TNF inhibitors.

Early pain relief suggests attenuation of central pain processing with JAK inhibitors.

The JAK inhibitor class slow radiographic progression.

There is objective measurable efficacy as early as 2 weeks with maximum effect beyond 3 months.

Upadacitinib + MTX combination demonstrates the highest ACR response rates among available JAK inhibitors.

$\mathrm{HZV}$ risk is acceptable and disseminated infection is rare.

There is an excess of VTE risk at higher doses and tofacitinib is only approved at $5 \mathrm{mg}$ BD in RA.

To date, there is no excess in cardiovascular risk at approved doses.

Meta-analyses have not revealed an increased risk of malignancy.

ACR and EULAR guidelines have incorporated JAK inhibitors into the RA treatment algorithm.

JAK inhibitors are likely to become increasingly used in RA in the coming decade.

\section{Disclosure}

The authors report no conflicts of interest for this work.

\section{References}

1. Favalli EG, Biggioggero M, Meroni PL. Methotrexate for the treatment of rheumatoid arthritis in the biologic era: still an "anchor" drug? Autoimmun Rev. 2014;13(11):1102-1108. doi:10.1016/j.autrev.2014. 08.026

2. Aletaha D, Smolen JS. The rheumatoid arthritis patient in the clinic: comparing more than 1300 consecutive DMARD courses. Rheumatology (Oxford). 2002;41:1367-1374. doi:10.1093/rheumatology/41.12.1367 
3. Gillinder KR, Tuckey H, Bell CC, et al. Direct targets of pSTAT5 signalling in erythropoiesis. PLoS One. 2017;12(7):e0180922. doi:10.1371/journal.pone. 0180922

4. Jak/Stat utilization table $\mid$ cell signaling technology. Cellsignal.co.uk. Available from: https://www.cellsignal.co.uk/contents/resourcesreference-tables/jak-stat-utilization-table/science-tables-jak-stat. Accessed July 14, 2020

5. Sikorski K, Czerwoniec A, Bujnicki JM, Wesoly J, Bluyssen HAR. STAT1 as a novel therapeutical target in pro-atherogenic signal integration of IFN $\gamma$, TLR4 and IL-6 in vascular disease. Cytokine Growth Factor Rev. 2011;22(4):211-219. doi:10.1016/j.cytogfr.2011.06.003

6. O'Shea J, Holland S, Staudt L. JAKs and STATs in immunity, immunodeficiency, and cancer. $N$ Engl $J$ Med. 2013;368 (2):161-170. doi:10.1056/NEJMra1202117

7. Waldmann TA, Chen J. Disorders of the JAK/STAT pathway in T cell lymphoma pathogenesis: implications for immunotherapy. Annu Rev Immunol. 2017;26:533-550. doi:10.1146/annurev-immunol-110416120628

8. Kiel MJ, Sahasrabuddhe AA, Rolland DCM, et al. Genomic analyses reveal recurrent mutations in epigenetic modifiers and the JAK-STAT pathway in Sézary syndrome. Nat Commun. 2015;29(6):8470. doi:10.1038/ncomms 9470

9. O'Sullivan JM, Harrison CN. JAK-STAT signaling in the therapeutic landscape of myeloproliferative neoplasms. Mol Cell Endocrinol. 2017;15:71-79. doi:10.1016/j.mce.2017.01.050

10. Barreiros LA, Segundo GRS, Grumach AS, et al. A novel homozygous JAK3 mutation leading to T-B+NK- SCID in two Brazilian patients. Front Pediatr. 2018;6:230. doi:10.3389/fped.2018.00230

11. Minegishi Y, Karasuyama H. Defects in Jak-STAT-mediated cytokine signals cause hyper-IgE syndrome: lessons from a primary immunodeficiency. Int Immunol. 2009;21(2):105-112. doi:10.1093/ intimm/dxn134

12. Wunderlich C, Hövelmeyer N, Wunderlich F. Mechanisms of chronic JAK-STAT3-SOCS3 signaling in obesity. JAKSTAT. 2013;2(2): e23878.

13. Garber K. Pfizer's first-in-class JAK inhibitor pricey for rheumatoid arthritis market. Nat Biotechnol. 2013;31(1):3-4. doi:10.1038/ nbt0113-3

14. Taylor P. Clinical efficacy of launched JAK inhibitors in rheumatoid arthritis. Rheumatology (Oxford). 2019;58:17-26. doi:10.1093/rheumatology/key225

15. Clark JD, Flanagan ME, Telliez JB. Discovery and development of Janus kinase (JAK) inhibitors for inflammatory diseases. $J$ Med Chem. 2014;57(12):5023-5038. doi:10.1021/jm401490p

16. Genovese MC, Kremer J, Zamani O, et al. Baricitinib in patients with refractory rheumatoid arthritis. $N$ Engl $J$ Med. 2016;374 (13):1243-1252. doi:10.1056/NEJMoa1507247

17. Yamaoka K. Janus kinase inhibitors for rheumatoid arthritis. Curr Opin Chem Biol. 2016;32:29-33. doi:10.1016/j.cbpa.2016.03.006

18. Lee E, Fleischmann R, Hall S, et al. Tofacitinib versus methotrexate in rheumatoid arthritis. $N$ Engl $J$ Med. 2014;370(25):2377-2386. doi:10.1056/NEJMoa1310476

19. Fleischmann R, Mease PJ, Schwartzman S, et al. Efficacy of tofacitinib in patients with rheumatoid arthritis stratified by background methotrexate dose group. Clin Rheum. 2017;36(1):15-24. doi:10.1007/s10067-016-3436-1

20. Fleischmann R, Mysler E, Hall S, et al. Efficacy and safety of tofacitinib monotherapy, tofacitinib with methotrexate, and adalimumab with methotrexate in patients with rheumatoid arthritis (ORAL Strategy): a Phase 3b/4, double-blind, head-to-head, randomised controlled trial. Lancet. 2017;390(10093):457-468.

21. Fleischmann R, Schiff M, van der Heijde D, et al. Baricitinib, methotrexate, or combination in patients with rheumatoid arthritis and no or limited prior disease-modifying antirheumatic drug treatment. Arthritis Rheumatol. 2017;69(3):506-517. doi:10.1002/ art.39953
22. Taylor P, Keystone E, van der Heijde D, et al. Baricitinib versus placebo or adalimumab in rheumatoid arthritis. $N$ Engl $J$ Med. 2017;376(7):652-662. doi:10.1056/NEJMoa1608345

23. Van der Heijde D, Durez P, Schett G, et al. Structural damage progression in patients with early rheumatoid arthritis treated with methotrexate, baricitinib, or baricitinib plus methotrexate based on clinical response in the phase III RA-BEGIN study. Clin Rheumatol. 2018;37(9):2381-2390. doi:10.1007/s10067-018-4221-0

24. Van Vollenhoven R, Takeuchi T, Pangan AL, et al. A phase 3, randomized, controlled trial comparing upadacitinib monotherapy to MTX monotherapy in MTX-naïve patients with active rheumatoid arthritis. Arthritis Rheumatol. 2018;70(Suppl 10).

25. Smolen JS, Cohen S, Emery P, et al. Upadacitinib as monotherapy: a phase 3 randomized controlled double-blind study in patients with active rheumatoid arthritis and inadequate response to methotrexate. Arthritis Rheumatol. 2018;70(Suppl 10).

26. Fleischmann R, Pangan AL, Mysler E, et al. A phase 3, randomized, double-blind study comparing upadacitinib to placebo and to adalimumab, in patients with active rheumatoid arthritis with inadequate response to methotrexate. Arthritis Rheumatol. 2018;70 (Suppl 10).

27. Lee YH, Song GG. Relative efficacy and safety of tofacitinib, baricitinib, upadacitinib, and filgotinib in comparison to adalimumab in patients with active rheumatoid arthritis [published online ahead of print, 2020 Feb 13]. Relative wirksamkeit und sicherheit von tofacitinib, baricitinib, upadacitinib und filgotinib im vergleich zu adalimumab bei patienten mit aktiver rheumatoider arthritis. $Z$ Rheumatol. 2020. doi:10.1007/s00393-020-00750-1

28. Fleischmann R, Mysler E, Hall S, et al. Efficacy and safety of tofacitinib monotherapy, tofacitinib with methotrexate, and adalimumab with methotrexate in patients with rheumatoid arthritis (ORAL Strategy): a phase $3 \mathrm{~b} / 4$, double-blind, head-to-head, randomised controlled trial. Lancet. 2017;390:457-468. doi:10.1016/S0140-6736(17) 31618-5

29. Combe B, Kivitz A, Tanaka Y, et al. Efficacy and safety of filgotinib for patients with rheumatoid arthritis with inadequate response to methotrexate: FINCH1 primary outcome results. 2019

30. Winthrop KL. The emerging safety profile of JAK inhibitors in rheumatic disease. Nat Rev Rheumatol. 2017;13:234-243. doi:10.1038/nrrheum.2017.23

31. Strand V, Ahadieh S, French J, et al. Systematic review and meta-analysis of serious infections with tofacitinib and biologic disease-modifying antirheumatic drug treatment in rheumatoid arthritis clinical trials. Arthritis Res Ther. 2015;17:362. doi:10.1186/ s13075-015-0880-2

32. Cohen SB, Tanaka Y, Mariette X, et al. Long-term safety of tofacitinib for the treatment of rheumatoid arthritis up to 8.5 years: integrated analysis of data from the global clinical trials. Ann Rheum Dis. 2017;76:1253-1262. doi:10.1136/annrheumdis-2016-210457

33. Smitten AL, Choi HK, Hochberg MC, et al. The risk of herpes zoster in patients with rheumatoid arthritis in the united states and the united kingdom. Arthritis Rheum. 2007;57(8):1431-1438. doi:10.1002/ art.23112

34. Choy E. Clinical significance of Janus Kinase inhibitor selectivity. Rheumatology. 2018;58(6):953-962. doi:10.1093/rheumatology/key339

35. Winthrop KL, Yamanaka H, Valdez H, et al. Herpes zoster and tofacitinib therapy in patients with rheumatoid arthritis. Arthritis Rheumatol. 2014;66(10):2675-2684. doi:10.1002/art.38745

36. Smolen JS, Genovese MC, Takeuchi T, et al. Safety profile of Baricitinib in patients with active rheumatoid arthritis with over 2 years median time in treatment. $J$ Rheumatol. 2019;46(1):7-18. doi:10.3899/jrheum.171361

37. Kiladjian JJ, Guglielmelli P, Griesshammer M, et al. Efficacy and safety of ruxolitinib after and versus interferon use in the RESPONSE studies. Ann Hematol. 2018;97(4):617-627. doi:10.1007/s00277-017-3225-1 
38. Besancenot R, Roos-Weil D, Tonetti C, et al. JAK2 and MPL protein levels determine TPO-induced megakaryocyte proliferation vs differentiation. Blood. 2014;124(13):2104-2115. doi:10.1182/blood2014-03-559815

39. Koride S, Nayak S, Banfield C, Peterson MC. Evaluating the role of janus kinase pathways in platelet homeostasis using a systems modeling approach. CPT Pharmacometrics Syst Pharmacol. 2019;8 (7):478-488. doi:10.1002/psp4.12419

40. Xie W, Huang Y, Xiao S, Sun X, Fan Y, Zhang Z. Impact of Janus kinase inhibitors on risk of cardiovascular events in patients with rheumatoid arthritis: systematic review and meta-analysis of randomised controlled trials. Ann Rheum Dis. 2019;78:1048-1054. doi:10.1136/annrheumdis-2018-214846

41. Maneiro JR, Souto A, Gomez-Reino JJ. Risks of malignancies related to tofacitinib and biological drugs in rheumatoid arthritis: systematic review, meta-analysis, and network meta-analysis. Semin Arthritis Rheum. 2017;47:149-156. doi:10.1016/j.semarthrit.2017.02.007

42. Taylor PC, Weinblatt ME, Burmester GR, et al. Cardiovascular safety during treatment with baricitinib in rheumatoid arthritis. Arthritis Rheumatol. 2019;71:1042-1055. doi:10.1002/art.40841

43. Charles-Schoeman C, Wicker P, Gonzalez-Gay MA, et al. Cardiovascular safety findings in patients with rheumatoid arthritis treated with tofacitinib, an oral Janus kinase inhibitor. Semin Arthritis Rheum. 2016;46(3):261-271. doi:10.1016/j.semarthrit.2016.05.014

44. Chikugo M, Sebe M, Tsutsumi R, et al. Effect of Janus kinase inhibition by tofacitinib on body composition and glucose metabolism. J Med Investig. 2018;65(3.4):166-170. doi:10.2152/ jmi.65.166

45. Ruxolitinib $\left(\mathrm{JAKAVI}^{\circ}\right)$ and polycythaemia vera Inconclusive evaluation. Prescrire Int. 2016;25(175):229-231.

46. Moisan A, Lee Y, Zhang J, et al. White-to-brown metabolic conversion of human adipocytes by JAK inhibition. Nat Cell Biol. 2014;17 (1):57-67. doi:10.1038/ncb3075

47. Fautrel B, Alten R, Kirkham B, et al. Call for action: how to improve use of patient-reported outcomes to guide clinical decision making in rheumatoid arthritis. Rheumatol Int. 2018;38:935-947. doi:10.1007/ s00296-018-4005-5

48. Taylor PC, Moore A, Vasilescu R, et al. A structured literature review of the burden of illness and unmet needs in patients with rheumatoid arthritis: a current perspective. Rheumatol Int. 2016;36:685-695. doi:10.1007/s00296-015-3415-x

49. Oude Voshaar M, Das Gupta Z, Van de Laar MA, et al. Op0329-hpr outcomes that matter to people living with inflammatory arthritis; a global standard set, developed by the international consortium for health outcome measurement (ICHOM) working group for inflammatory arthritis. Ann Rheum Dis. 2018;77:211.

50. Heiberg T, Kvien TK. Preferences for improved health examined in 1024 patients with rheumatoid arthritis: pain has highest priority. Arthritis Rheum. 2002;47(4):391-397. doi:10.1002/art.10515

51. Rifbjerg-Madsen S, Christensen AW, Christensen R, et al. Pain and pain mechanisms in patients with inflammatory arthritis: a Danish nationwide cross-sectional DANBIO registry survey. PLoS One. 2017;12(7):e0180014. doi:10.1371/journal.pone.0180014

52. Salaffi F, Giacobazzi G, Di Carlo M. Chronic pain in inflammatory arthritis: mechanisms, metrology, and emerging targets - a focus on the JAK-STAT pathway. Pain Res Manag. 2018;2018:8564215. doi:10.1155/2018/8564215

53. Fitzcharles M-A, Shir Y. Management of chronic pain in the rheumatic diseases with insights for the clinician. Ther Adv Musculoskelet Dis. 2011;3(4):179-190. doi:10.1177/1759720X11408999

54. Busch-Dienstfertig M, Gonzalez-Rodriguez S. Il-4, JAK-STAT signaling, and pain. JAKSTAT. 2013;2(4):e27638.

55. Wallenstein GV, Kanik KS, Wilkinson B, et al. Effects of the oral Janus kinase inhibitor tofacitinib on patient-reported outcomes in patients with active rheumatoid arthritis: results of two Phase 2 randomised controlled trials. Clin Exp Rheum. 2016;34(3):430-442.
56. Fautrel B, Zhu B, Taylor PC, et al. Comparative effectiveness of improvement in pain and physical function for baricitinib versus adalimumab, tocilizumab and tofacitinib monotherapies in rheumatoid arthritis patients who are naive to treatment with biologic or conventional synthetic disease modifying antirheumatic drugs: a matching-adjusted indirect comparison. RMD Open. 2020;6: e001131.

57. Taylor PC, Lee YC, Fleischmann R, et al. Achieving pain control in rheumatoid arthritis with baricitinib or adalimumab plus methotrexate: results from the RA-BEAM trial. J Clin Med. 2019;8(6):831. doi: $10.3390 / \mathrm{jcm} 8060831$

58. Smolen JS, Landewé RBM, Bijlsma JWJ, et al. EULAR recommendations for the management of rheumatoid arthritis with synthetic and biological disease-modifying antirheumatic drugs: 2019 update. Ann Rheum Dis. 2020;79:685-699. doi:10.1136/annrheumdis-2019216655

59. Singh J, Saag K, Bridges S, et al. 2015 American College of Rheumatology guideline for the treatment of rheumatoid arthritis. Arthritis Care Res (Hoboken). 2015;68(1):1-25. doi:10.1002/ acr. 22783

60. Institute for Clinical and Economic Review. ICER issues final report and policy recommendations on JAK inhibitors for rheumatoid arthritis internet document: 9 Jan 2020. Available from: https://icer-review.org/ announcements/icer-issues-final-report-and-policy-recommendationsfor-rheumatoid-arthritis-therapies/. Accessed August 18, 2020.

61. Joint Formulary Committee. British National Formulary: BNF. 76. Pharmaceutical Press; 2018.

62. Centers for Medicare and Medicaid Services. "NADAC as of 201902-27'. Retrieved 3 March, 2019.

63. Fleischmann R, Kremer J, Cush J, et al. Placebo-controlled trial of tofacitinib monotherapy in rheumatoid arthritis. $N$ Engl $\mathrm{J} \mathrm{Med.}$ 2012;367(6):495-507. doi:10.1056/NEJMoa1109071

64. van Vollenhoven RF, Fleischmann R, Cohen S, et al. Tofacitinib or adalimumab versus placebo in rheumatoid arthritis. $N$ Engl $J$ Med. 2012;367(6):508-519. doi:10.1056/NEJMoa1112072

65. van der Heijde D, Tanaka Y, Fleischmann R, et al. Tofacitinib (CP-690,550) in patients with rheumatoid arthritis receiving methotrexate: twelve-month data from a twenty-four-month phase III randomized radiographic study. Arthritis Rheum. 2013;65(3):559-570. doi:10.1002/art.37816

66. Burmester GR, Blanco R, Charles-Schoeman C, et al. Tofacitinib (CP-690,550) in combination with methotrexate in patients with active rheumatoid arthritis with an inadequate response to tumour necrosis factor inhibitors: a randomised phase 3 trial. Lancet. 2013;381(9865):451-460. doi:10.1016/S0140-6736(12)61424-X

67. Lundquist LM, Cole SW, Sikes ML. Efficacy and safety of tofacitinib for treatment of rheumatoid arthritis. World J Orthop. 2014;5 (4):504-511. doi:10.5312/wjo.v5.i4.504

68. Strand V, Fleischmann R, Alten RE, et al. THU0258 oral start: effects of the oral JAK inhibitor tofacitinib monotherapy versus methotrexate on patient-reported outcomes in the phase 3 oral start trial of active rheumatoid arthritis. Ann Rheum Dis. 2013;72:A252-A253. doi:10.1136/annrheumdis-2013-eular.786

69. Wollenhaupt J, Lee EB, Curtis JR, et al. Safety and efficacy of tofacitinib for up to 9.5 years in the treatment of rheumatoid arthritis: final results of a global, open-label, long-term extension study. Arthritis Res Ther. 2019;21(1):89. doi:10.1186/s13075-019-1866-2

70. Keystone EC, Taylor PC, Drescher E, et al. Safety and efficacy of baricitinib at 24 weeks in patients with rheumatoid arthritis who have had an inadequate response to methotrexate. Ann Rheum Dis. 2015;74:333-340. doi:10.1136/annrheumdis-2014-206478

71. Tanaka Y, Emoto K, Cai Z, et al. Efficacy and safety of baricitinib in Japanese patients with active rheumatoid arthritis receiving background methotrexate therapy: a 12-week, double-blind, randomized placebo-controlled study. J Rheumatol. 2016;43(5):998. doi:10.3899/ jrheum. 150613 
72. Genovese MC, Kremer JM, Kartman CE, et al. Response to baricitinib based on prior biologic use in patients with refractory rheumatoid arthritis. Rheumatology (Oxford). 2018;57(5):900-908. doi:10.1093/rheumatology/kex489

73. Dougados M, van der Heijde D, Chen Y, et al. Baricitinib in patients with inadequate response or intolerance to conventional synthetic DMARDs: results from the RA-BUILD study. Ann Rheum Dis. 2017;76:88-95. doi:10.1136/annrheumdis-2016-210094

74. Fautrel B, Kirkham B, Pope JE, et al. Effect of baricitinib and adalimumab in reducing pain and improving function in patients with rheumatoid arthritis in low disease activity: exploratory analyses from RA-BEAM. J Clin Med. 2019;8(9):1394. doi:10.3390/ jcm8091394

75. Li Z, Hu J, Bao C, et al. SAT0218 Efficacy and safety of baricitinib in mtx-ir patients with rheumatoid arthritis: 52 week results from a phase 3 study (RA-BALANCE). Ann Rheum Dis. 2018;77:969-970.

76. Fleischmann R, Takeuchi T, Schiff M, et al. Efficacy and safety of long-term baricitinib with and without methotrexate for the treatment of rheumatoid arthritis: experience with baricitinib monotherapy continuation or after switching from methotrexate monotherapy or baricitinib plus methotrexate. Arthritis Care Res (Hoboken). 2019 doi:10.1002/acr.24007

77. Genovese MC, Fleischmann R, Combe B, et al. Safety and efficacy of upadacitinib in patients with active rheumatoid arthritis refractory to biologic disease-modifying anti-rheumatic drugs (SELECT-BEYOND): a double-blind, randomised controlled phase 3 trial. Lancet. 2018;391(10139):2513-2524. doi:10.1016/S01406736(18)31116-4

78. Burmester GR, Kremer JM, Van den Bosch F, et al. Safety and efficacy of upadacitinib in patients with rheumatoid arthritis and inadequate response to conventional synthetic disease-modifying anti-rheumatic drugs (SELECT-NEXT): a randomised, double-blind, placebo-controlled phase 3 trial. Lancet. 2018;391 (10139):2503-2512. doi:10.1016/S0140-6736(18)31115-2

79. Smolen JS, Pangan AL, Emery P, et al. Upadacitinib as monotherapy in patients with active rheumatoid arthritis and inadequate response to methotrexate (SELECT-MONOTHERAPY): a randomised, placebo-controlled, double-blind phase 3 study. Lancet. 2019;393 (10188):2303-2311. doi:10.1016/S0140-6736(19)30419-2

80. Rubbert-Roth A, Enejosa J, Pangan A, et al. Efficacy and safety of upadacitinib versus abatacept in patients with active rheumatoid arthritis and prior inadequate response or intolerance to biologic disease-modifying anti-rheumatic drugs (SELECT-Choice): a double-blind, randomised controlled phase 3 trial. Ann Rheum Dis. 2020;79:1015-1016.

81. Fleischmann RM, Genovese MC, Enejosa JV, et al. Safety and effectiveness of upadacitinib or adalimumab plus methotrexate in patients with rheumatoid arthritis over 48 weeks with switch to alternate therapy in patients with insufficient response. Ann Rheum Dis. 2019;78:1454-1462. doi:10.1136/annrheumdis-2019-215764
82. Vollenhoven RV, Takeuchi T, Pangan A, et al. Monotherapy with upadacitinib in MTX-naïve patients with rheumatoid arthritis: results at 48 weeks from the SELECT-early study. Ann Rheum Dis. 2019;78:376-377.

83. Westhovens R, Taylor PC, Alten R, et al. Filgotinib (GLPG0634/ GS-6034), an oral JAK1 selective inhibitor, is effective in combination with methotrexate (MTX) in patients with active rheumatoid arthritis and insufficient response to MTX: results from a randomised, dose-finding study (DARWIN 1). Ann Rheum Dis. 2017;76(6):998-1008. doi:10.1136/annrheumdis-2016-210104

84. Kavanaugh A, Kremer J, Ponce L, et al. Filgotinib (GLPG0634/ GS-6034), an oral selective JAK1 inhibitor, is effective as monotherapy in patients with active rheumatoid arthritis: results from a randomised, dose-finding study (DARWIN 2). Ann Rheum Dis. 2017;76(6):1009-1019. doi:10.1136/annrheumdis-2016-210105

85. Genovese MC, Kalunian K, Gottenberg JE, et al. Effect of filgotinib vs placebo on clinical response in patients with moderate to severe rheumatoid arthritis refractory to disease-modifying antirheumatic drug therapy: the FINCH 2 randomized clinical trial. JAMA. 2019;322(4):315-325. doi:10.1001/jama.2019.9055

86. Takeuchi T, Tanaka Y, Iwasaki M, Ishikura H, Saeki S, Kaneko Y. Efficacy and safety of the oral Janus kinase inhibitor peficitinib (ASP015K) monotherapy in patients with moderate to severe rheumatoid arthritis in Japan: a 12-week, randomised, double-blind, placebo-controlled phase IIb study. Ann Rheum Dis. 2016;75 (6):1057-1064. doi:10.1136/annrheumdis-2015-208279

87. Takeuchi T, Tanaka Y, Tanaka S, et al. Safety and effectiveness of peficitinib (ASP015K) in patients with rheumatoid arthritis: interim data (22.7 months mean peficitinib treatment) from a long-term, open-label extension study in Japan, Korea, and Taiwan. Arthritis Res Ther. 2020;22:1-3.

88. Tanaka Y, Takeuchi T, Tanaka S, et al. Efficacy and safety of peficitinib (ASP015K) in patients with rheumatoid arthritis and an inadequate response to conventional DMARDs: a randomised, double-blind, placebo-controlled phase III trial (RAJ3). Ann Rheum Dis. 2019;78:1320-1332. doi:10.1136/annrheumdis-2019-215163

89. Takeuchi T, Tanaka Y, Tanaka S, et al. Efficacy and safety of peficitinib (ASP015K) in patients with rheumatoid arthritis and an inadequate response to methotrexate: results of a phase III randomised, double-blind, placebo-controlled trial (RAJ4) in Japan. Ann Rheum Dis. 2019;78:1305-1319. doi:10.1136/annrheumdis-2019-215164

90. A study exploring the safety, tolerability, and efficacy of a 28 day course followed by an additional 56 day course of itacitinib in subjects with active rheumatoid arthritis - full text view ClinicalTrials.gov. Available from: https://clinicaltrials.gov/ct2/ show/NCT01626573. Accessed August 18, 2020.

91. A study exploring the safety, tolerability and efficacy of a 4 week course of INCB018424 in subjects with active rheumatoid arthritis full text view - ClinicalTrials.gov. Available from: https://clinical trials.gov/ct2/show/study/NCT00550043. Accessed August 18, 2020.
Journal of Inflammation Research

\section{Publish your work in this journal}

The Journal of Inflammation Research is an international, peerreviewed open-access journal that welcomes laboratory and clinical findings on the molecular basis, cell biology and pharmacology of inflammation including original research, reviews, symposium reports, hypothesis formation and commentaries on: acute/chronic inflammation; mediators of inflammation; cellular processes; molecular mechanisms; pharmacology and novel anti-inflammatory drugs; clinical conditions involving inflammation. The manuscript management system is completely online and includes a very quick and fair peerreview system. Visit http://www.dovepress.com/testimonials.php to read real quotes from published authors. 